Introduction

Historically, public health guidelines promote the addition of physical activity exemplified in terms of aerobic exercise and resistance training for cardiorespiratory fitness and musculoskeletal health. The exercise prescription is seen as an aid in preventive disease medicine (Winett and Carpinelli, 2001), an activity to increase selfesteem (Spence et al., 2005), and is used in a variety of psychiatric therapeutic interventions. However, when exercise is performed excessively, the practice can adapt as a pathological association of body image disorders. Traditionally, this association has been confined largely to the relationship between aerobic exercise and eating disorders in women who aspire to unattainable levels of thinness. However, research has illustrated a growing prevalence of body image dissatisfaction among men, which posits that both men and boys as young as 6 years reportedly desire a physique that differs from their current perceptions of self (Pope et al., 2000). College aged men reported that the ideal masculine body carries, on average, 25 pounds more muscle than their own physique (Olivardia et al., 2004). In addition, males as a cohort desire to gain approximately 17 pounds of muscle mass, regardless of their current shape (Pope et al., 2000).

The reasons for this apparently increasing trend towards increasing body dissatisfaction amongst males may lie in the increasing promotion of lean, heavilymuscled body as the male ideal (Andersen, 2002; Grieve, 2007). Mesomorphic males are viewed as more socially desirable and possessing greater physical and athletic prowess than ectomorphic males (Pope, Phillips and Olivardia, 2000). At the same time, 
over recent decades the cultural norm for the ideal male physique has become increasingly more muscular (Leit, Pope and Gray, 2001). Therefore, it is perhaps not surprising that an increasing number of males report body dissatisfaction (Phillips and Drummond, 2001) and an increased desire for a lean, heavily muscled physique (Leone, Sedory and Gray, 2005). A recent survey (Field et al., 2014) found that almost $18 \%$ of adolescent boys were concerned about not being muscular enough; perhaps not surprising when even toy action figures have increased in muscularity in recent years to the point where they have physiques that in many cases would be unattainable even for the most advanced bodybuilders (Baghurst, Hollander, Nardella and Haff, 2006).

Given the above, we argue that body image dissatisfaction should be a concern to all those interested in mental health. The following sections of this chapter describe how such dissatisfaction drives physique-enhancing behaviors that can reach clinical and debilitating levels. Firstly, relevant psychiatric disorders of body dysmorphic disorder and muscle dysmorphia will be explained, and the relationship between muscle dysmorphia and the use of physique-enhancing drugs will be explored. Psychological and socio-cultural factors influencing this relationship will be examined, and suggestions made for future research.

Body Dysmorphic Disorder and Muscle Dysmorphia

Body dysmorphic disorder (BDD) is a severe psychiatric disorder characterized by time-consuming preoccupations with one or more perceived defects or flaws in appearance that are not observable or appear slight to others. (Kelly, Didie and Phillips, 2014). BDD-related preoccupations cause clinically significant distress or impairment in 
functioning. BDD is often accompanied by repetitive behaviors or mental acts that occur in response to the appearance preoccupations (e.g., mirror checking, skin picking, excessive grooming, comparing with others; American Psychiatric Association, 2013, and Phillips, 2005). Muscle Dysmorphia (MD) represents the pathological pursuit of muscularity and is characterized by an intensely distressing preoccupation that one is of insufficient muscularity (although appearing normal or muscular) coupled with rigorous exercise and dietary practices that take precedence over other important areas of life. As a subtype of $B D D, M D$ is unique in its form of causing preoccupation with the body as a whole, instead of a specific body part as seen in typical BDD.

MD was first noted in research as "reverse anorexia" (Pope, Katz and Hudson, 1993) and explained as the male version of the disorder anorexia nervosa, much like the female's need for thinness, as males experiencing this disorder are often concerned with losing weight (Murray et al., 2010). However, it was also recognized that minimizing body fat and maximizing muscularity is the generalized need or want by those with MD, rather than solely the fear of losing mass. As noted in our introduction, pressure has increased for the male ideal body type to appear muscular, inversely related to the ideal female body type to appear thin. This pressure has aided in men and women feeling dissatisfied in the way their bodies appear and in some cases a distorted body image is experienced. As a result, affected individuals may neglect important social or occupational activities because of shame over their perceived appearance flaws or their need to attend to a meticulous diet and time-consuming workout schedule (Pope et al., 2005). 


\section{Diagnostic Criteria}

A coherent line of research emerged after the introduction of the concept of reverse anorexia, and the term "Muscle Dysmorphia" was first introduced by Pope Jr. et al. (1997), along with a series of diagnostic criteria for the disorder. The concept of MD was proposed as a form of BDD as it was found in Pope et al.'s study that $9.3 \%$ of 193 individuals with already diagnosed BDD portrayed associated features of what would be explained as MD. The essential feature of MD is characterized as the severe need to be overly muscular and lean, which in turn causes significant impairment and distress in daily life. The symptoms of the disorder cause a distortion of reality and individuals with MD obsessively compare themselves to others with the notion that in most cases, they are smaller, no matter what the reality. It is frequently observed that individuals with MD will feel levels of extreme embarrassment and anxiety when forced to present their body in the public eye.

Following the early research, MD was recognized in the Diagnostic and Statistical Manual of Mental Disorders: Text Revision (American Psychiatric Association, 2000; DSM-IV) as a subtype of BDD categorized in the somatoform spectrum, a type of mental illness that causes physical symptoms. As research continued, no evidence for MD relating to a somatoform disorder was found, and in the DSM-V, published in 2013, the diagnosis of MD now lies in the obsessive-compulsive spectrum as a subtype of BDD.

Cafri et al. (2008) and Olivardia et al. (2000) revealed that symptoms of MD start manifesting at about 19.5 years of age. The symptoms of MD these authors noted were 
as follows: compulsive mirror checking, extensive time spent exercising, thinking about their muscularity $>30$ times a day, avoidance of people, places, and activities related to their body appearance, and abuse of performance enhancing drugs. Guy, Olivardia and Thompson (2008) found that $67 \%$ of their subjects with MD reportedly thought about their muscularity more than 3 hours daily. It is well documented that MD affects an individual on a behavioral, cognitive, and social level. Behavioral symptoms studied include pharmacological use, workout rituals, supplement use and dietary behavior. Psychological factors include exercise dependence, protection of physique and body size/symmetry (Rohman, 2009). When MD behavior characteristics continue to grow in an individual, negative consequences such as alienation, narcissism, and positive deviance may develop.

Another diagnostic specific of MD is the presence of comorbid psychological disorders. MD has been associated with higher rates of lifetime mood disorders such as major depressive disorder (Wolke and Sapouna, 2008). Anxiety disorders have also been associated with the development of MD such as panic disorder, posttraumatic stress disorder, obsessive-compulsive disorder (OCD), and generalized anxiety disorder. (Guy, Olivardia and Thompson, 2008). In fact, MD has also been categorized as a subtype of OCD (Dawes and Mankin, 2004). OCD as a form of anxiety encompasses obsessive rituals to overcome levels of anxious distress. The compulsive rituals in MD include the overwhelming time spent training in exercise, nutrition and the use of performance enhancing drugs to aid in muscular development; it is the ritualistic nature of behaviours performed to alleviate levels of physique-related anxiety in MD that has led to such an association. 
Approaches began comparing MD and the pathology following that of an eating disorder, and the most recent literature revisits the association. Researchers have proposed that MD presentations of body dysmorphic disorder do not generally include food and exercise-related psychopathology, and the diagnostic criteria for body dysmorphic disorder posit that those experiencing such concerns, in conjunction with shape-related body image and weight distortion, are best accounted for by an eating disorder diagnosis (Murray and Touyz, 2013). Scopes have therefore reanalyzed MD through the lens of an eating disorder and found that levels of functional impairment have closely aligned.

Perhaps the most comprehensive attempt to date to provide an allencompassing model of muscle dysmorphia has been that of Lantz, Rhea and Mayhew (2001), whose conceptual model included many of the factors noted above. They identified two precipitating factors, self-esteem and body dissatisfaction, that increase motivation to engage in exercise aimed at physique development. The development of muscles then increases self esteem, which will increase commitment to the exercise regime, and this is problematic if a person's self-esteem becomes dependent on this connection.

The six behavioural characteristics that develop from muscle dysmorphia, according to Lantz et al.'s model, include body size/symmetry (e.g., concern with developing an "ideal" muscular body), dietary constraints (e.g., consumption of an optimal "muscle building" diet), physique protection (e.g., hiding the physique with baggy clothing), supplement use (e.g., protein supplements), pharmacological abuse (e.g., use of anabolic-androgenic steroids), and exercise dependence (i.e., compulsive 
exercise). Each characteristic could then maintain a cyclical influence of more pathological behaviours. For example, as a person's attitude towards his or her body becomes more pathological, he or she may begin to experiment with muscle-building drugs. As his or her physique develops, he or she will associate this with the pharmacological intervention, and so that behaviour is increasingly reinforced.

The overall prevalence of MD is under researched yet estimated by Olivardia (2007) as 100,000 cases in the United States. It was noted that there is an assumption that a much larger quantity of individuals experience less severe versions of the disorder. Females have been found to experience most forms of BDD, yet MD has been found to be more prevalent in men. The natures of MD and BDD are such that individuals will likely not admit their disorder, or seek help, because of embarrassment. This makes it difficult to accurately estimate a prevalence of BDD and MD.

\section{Muscle Dysmorphia and Body Building/Weight Lifting}

It is important to note the difference between body builders and weight lifters, as both terms are often used interchangeably. A "weight lifter" is an individual who undergoes the process of exercise in the form of resistance training to control and develop one's musculature. A "body builder" is a vague term in which a varying level of dedication is prospered into developing one's musculature from an amateur to professional level while participating in competitions to display their physique. They have been found to carry the highest level of body dissatisfaction compared to other competitive athletic groups (Blouin and Goldfield, 1995), and are predominately used in MD literature; the nature of muscle maintenance and development between weight 
lifters and body builders respectively allow them to serve for a pinpointed population regarding body image disorders alike.

A vast majority of those susceptible to MD start lifting weights in their adolescent years in the hope of building a muscular physique to cover up their inner insecurities. However, even after attaining considerable muscle mass the insecurities persist (Rohman, 2009). The research question naturally arises whether participation in lifting weights and/or bodybuilding is a precursor to developing body image pathology and increasingly into BDD/MD? This was addressed in Olivardia, Pope and Hudson's (2000) study when comparing 24 men with MD and 30 normal weightlifters. The men with MD differed significantly on measures of body dissatisfaction, eating behaviors, prevalence of steroid usage, and lifetime prevalence of DSV-IV related mood, anxiety, and eating disorders. It was found that the normal weightlifters portrayed little psychopathology compared to the weightlifters with MD.

Individuals with MD are distinct from normal weight lifters in their symptom pathology and psychiatric comorbidity (Guy, Olivardia and Thompson, 2008). For weight lifters to be diagnosed with MD, they must show a level of functional impairment. Those with the disorder have reported lifting weights 7 days a week and more than once a day for an hour and a half at each session. Studies have shown that a typical weight lifting routine significantly differs from the compulsive over training seen in those with MD. They tend to deny occupational opportunities because holding a job does not allow them to engage in extensive weight lifting and eating habits, which are a priority in the functioning of their lives (for example, see Fussell, 1991). Others have explained that 
living alone also diminishes stress of a significant other tampering with their strict regime. Therefore, there should not be confusion between mere enthusiasm in a dedicated lifestyle of bodybuilding and MD. The difference lies in profound levels of extreme distress and maladaptive coping behaviours.

\section{Muscle Dysmorphia and Performance Enhancing Drugs}

Referring to the first published study on MD (or "reverse anorexia" as it was referred to by Pope et al., 1993), all nine participants then who were found to portray to what would later be developed as MD were using anabolic androgenic steroids (AAS). Research began exploring this association and amongst the many rituals to require more mass found in those with MD, the use of anabolic androgenic steroids (AAS) has been the most frequently associated. Many report that use of AAS is aimed at curing their disorder, yet others have explained that the use of the steroids aided in the development of their hyper-mesomorphic physique preoccupation.

To appreciate the role that AAS may play in the lives of those experiencing muscle dysmorphia, an understanding of the impact AAS use has on those choosing to use is needed. Sagoe, Andreassen, and Pallesen (2014) conducted a literature review of 44 qualitative studies concerning AAS use, a found a myriad of reasons for initiating use. However, the 3 main reasons for initiation of use were: 1) wanting success in sports participation (particularly power sports), 2) to overcome negative body image, and 3) dealing with psychological disorders such as depression. 
Once AAS use was initiated, several studies (Olrich, 1993; Olrich and Ewing, 1999; Petrocelli, Oberweiss and Petrocelli, 2008; Vassallo and Olrich, 2010) found the AAS use period to have a profound impact on the users. Users experienced significant positive increases in muscle mass, strength, and self-confidence, which will discussed below and will draw heavily from research conducted by the authors of this chapter.

Perceived Benefits of AAS Use. In a study of competitive and non-competitive bodybuilders, Olrich and Ewing (1999) reported that 9 of 10 AAS users spoke of the AAS use period in very positive terms, while in a study of former collegiate athletes, Vassallo and Olrich (2010) found all 38 participants perceived their AAS use period positively. Participants using AAS experienced rapid and profound increases in strength, power and muscle mass. Those gains led to a number of positive corollary benefits, including greater peer recognition, greater perceived sexual attractiveness and greater success in sport. The following responses capture such positive benefits:

"Physically, Stronger. I felt like training all the time. I loved coming into the gym, because I could hoist all these heavy poundages. I was making good gains. The pump I got was incredible. When you get pumped, I mean you could see man, you're looking huge and ripped. And it was just unbelievable. It really motivated you to get into the gym." (Olrich, 1993).

"I am personally a lot more energetic and aggressive, probably a combination of those two words. Needless to say, I'm a lot more confident and potentially cocky for the fact that what happens is I'm looking physically better, be it bloated or not. I tend to be a bit more cut when I'm on drugs, so I tend to look a little better. My 
muscular definition is coming out, my strength is increasing, so each time (I'm in the gym) I try to obtain a new goal. I'm obtaining goals and as with anyone in life, when you try for something to obtain goals, you feel great. You feel great because you can do it. I can do anything. I'm more horny. I'm more aggressive. I just tend to attack things a lot more and everything seems to be clicking. I feel better. I'm stronger. You do, you have to sleep because you're training hard, but you don't feel like you have to have as much sleep. You tend to be on top of the world. I don't know, I guess I like that feeling. (Olrich and Ewing, 1999).

"Oh, positive for sure. Because I kept my spot in baseball, and I developed a chiseled body, and my grades went through the roof. I never got a better grade point than during those semesters I used the juice." (Vassallo and Olrich, 2010).

As these quotes point out, the AAS use experience had a powerful effect on the men, and the benefits went well beyond the walls of the gym. Further, the men perceived significant increases in self-confidence and peer recognition. The following quotes were from athletes who used during their college sporting career as reported by Vassallo and Olrich (2010) when asked if their levels of confidence were impacted by AAS use:

"Is the Pope catholic? Of course they were. That was the sole reason I took three more cycles throughout college. I felt like I was on top of the world anytime I was on the juice."

Another of the participants had this to say: 
(Levels of confidence) "They were as big as the frickin sky. I was the man and you better bring your best or I would rip your f---g head off. I knew that when I was on the 'roids I could do some major hitting compared to when I was off the shit. I, you know, I was meaner than hell and I needed those things to help me get that edge."

And another stated:

"I was, I don't know if this is proper, but I felt like the f---g man. I mean I was just invincible. I felt I could do anything I put my mind to, and 9 times out of 10 I did. That was the best I ever felt about myself. Man, I miss that feeling."

And the statement by another participant captured the sentiment well:

"That is an understatement if I ever heard one before. I mean I felt like I could climb the tallest mountain with no training if I needed to. I know that is a stupid analogy. But I was more confident than I ever was in my life when I was on the steroids. I am a very confident individual without the 'roids (sic) and when I was on the stuff it was absolutely amazing how my confidence levels just soared through the roof. I loved that feeling."

Similar responses were found with competitive and recreational bodybuilders (Olrich and Ewing, 1999):

"Oh yeah. King of the world, It's just a good feeling. You can just think straight. It's just a good feeling. But you just feel...you just think differently about 
situations. You react differently. You feel good about yourself, and you know you've got the edge. And that affects you through your whole cycle, whether you're training or not. You've got the edge."

Perceived positive increases in both self-image and self-confidence were also due to peer recognition which many of the participants discussed.

'When you're on steroids, if you're bigger, you're stronger, and you're getting personal recognition from your peers...you're enjoying it. You're enjoying the peer recognition. If you're on steroids, and because you're on steroids you grow, people are noticing you. You're lifting more weight, or whatever the scenario is, that you're getting more peer recognition."

AAS and Psychological Addiction. Participants in these studies (Olrich, 1993; Olrich and Ewing, 1999; Olrich and Vassallo, 2006; Vassallo and Olrich, 2010) were queried concerning their perceptions as to whether AAS had any potential to be psychologically addictive. Not surprisingly, considering the responses given above, all of the men interviewed believed that AAS had a strong potential for psychological addiction, whether the men believed they experienced such an addiction or not. Representative statements from the bodybuilders are given below:

"Sure. I know definitely there is (a psychological dependence). There's definitely. I know that. I know for a fact that, because I have troubles when I do a cycle coming off. Because you see, you like how they make you feel, okay? Mentally, they just do something to you. You feel great. And then you get so much 
stronger. And you blow right up. And you puff up, you know. And you look good. And you put on the weight. And that's what bodybuilders wants to do the most, is that you get that weight. And you want to get that weight up. And it comes like nothing man. And it's just there. And then it goes. Just like it came. You keep some, but you lose the majority. You do keep some. And you lose the edge. You lose that strength, that cockiness. You know, all the good things that come, that you feel from them, just go away."

Another bodybuilder spoke in a similar manner, but discussed the role of peer recognition in the process:

"I've never been on drugs where, "Oh my God, I have to have a shot, or I have to have a pill." I've never met anybody that's that way. But, they definitely want the effects of being big, because the side effects of that. The side effects being that they are getting peer recognition or personal recognition of some sort. "God, you're really growing," "God, you look great." "God, you're stronger than shit." People thrive off that, and you can't tell me in our society that people don't thrive off of recognition."

The former collegiate athletes of Vassallo and Olrich (2010) also spoke to the strength of this perceived, powerful dependency to AAS. One of the former football players stated:

"Of course there is man (a psychological addiction). I mean that is the main reason that me and my friends would do the shit again and again. We missed the 
feeling it gives you against your opponent. It was $f-g$ awesome. Yeah, the strength you get is great, but the reason I did the shit time and again was due to the fact that I wanted the mental edge it gives you."

Another football player who had also experimented with a variety of recreational drugs stated how he felt the addictive qualities of AAS were stronger than any other substance he had tried (Olrich and Vassallo, 2006).

"I know this sounds crazy, but I really think that they are more addictive than any recreational drug I have tried in my life. I mean once you have that feeling of invincibility you never want it to go away. It was something I needed more and more the older I got. I mean the last four cycles that I did (during his college career) was due to the fact that I missed the mental edge that I had over my opponent."

Another powerful statement from a former athlete is given below:

"There definitely is an addiction there that affects your mind. I think it is because the stuff gives you a mental edge that you will never experience in your life unless you do the stuff. I know it is not easy for someone to believe, but I promise you that the stuff gives you a mental boost in everything you do. It is f--ing awesome. I hope people realize that this is why the majority of people decide to do the stuff more and more. It just gives seems to give you an edge that is far more than the physical aspect that everyone thinks about. Physical strength you 
get from the stuff is great. But I promise you the stuff that you miss when you are done with your cycle is the edge that the stuff gives you in the head."

The AAS Use Experience and Muscle Dysmorphia. The participants quoted in the studies discussed above were not assessed for muscle dysmorphia. Yet, the nature of the comments given by the participants show the profound impact AAS would likely have on those who may have such a condition. The men had seemingly profound increases in strength, power, muscle mass, self-confidence, and they felt mentally they had "the edge". As the men discussed, the impact of AAS was felt throughout all aspects of their lives. Their perceptions of psychological addiction to AAS were insightful, noting the breadth of the impact of AAS on their lives and how that contributed to the addictive nature of the substances. Given this, it is not surprising that as noted above studies have found that many of those exhibiting symptoms of MD are AAS users, and indeed Lantz, Rhea and Mayhew's (2001) conceptual model of MD includes pharmacological use as one of the behaviours that characterizes those with MD. Cafri et al. (2005) also suggested that MD often culminates in AAS use to try to increase muscularity. The findings of Davies, Smith and Collier (2011) seem to support the idea that steroids are often used for this purpose, and also suggest that they may be successful in this regard for some bodybuilders. In this study, interviews were conducted with current and former AAS users to explore symptoms of MD. Interestingly, the current users were generally happy with their physiques, whereas body dissatisfaction was much more evident in the former users and they were more likely to engage in physique protection behaviors. Also, symptoms of exercise dependence were more prevalent in the former users, which the authors attributed to the fact that they 
were no longer using AAS so felt they had to work harder to maintain their size. Indeed, two of the former users interviewed were considering re-using the drugs as they felt they looked better when taking them.

Thus, there is some evidence that the use of AAS may be motivated by feelings of MD, and also that AAS use is associated with improved body satisfaction, but that this evaporates with cessation of use as the muscular gains produced by the drugs diminish. Given that AAS users appear to mostly view the experience of AAS use as positive despite the attendant health risks, and that recidivism is common in former users, trying to persuade users that such use is not in their best interests may be very challenging. Also, treating those with symptoms of MD is complicated by the often attendant drug use. The following section will explore the treatment issue and offer some tentative suggestions.

\section{Treatment of those with MD}

There are a number of challenging barriers to overcome in treating MD. The first one of these is that the vast majority of individuals with MD will not seek treatment (Pope, Philips and Olivardia, 2000). It is traditionally seen as vain for males to be concerned about their body's appearance, and therefore they may well be reluctant to open up to others about their body image concerns or even to admit them to themselves. They are likely to present to medical doctors for other reasons, such as weight training injuries, or concern regarding health issues relating to their AAS use. It is therefore important that GPs, physiotherapists and other health professionals are made aware of the symptoms of MD so they can recognize it in their patients. Competitive 
bodybuilders with symptoms of MD may present to coaches or sport psychologists for performance enhancement issues, so again it is important that the coach and sport psychologist can identify and understand this issue. The crucial thing here is for such professionals to encourage individuals to talk openly about body image concerns and show understanding that such concerns are perfectly normal and indeed commonplace.

Another factor that can make MD difficult to treat is the harmful and unrealistic portrayal of the human body in the media and society at large; the increasingly muscular portrayal of the male physique noted above not only makes MD more likely to occur, but makes it difficult to treat. Given the pervasiveness of muscular images, from action toys to male models and even movie stars (including many AAS users), individuals are constantly reminded that their physiques do not seem to 'measure up', and thus messages from professionals who are trying to treat an individual with MD have to compete against these much more pervasive and alluring ones.

That said, it is far from the case that there is nothing that psychologists, psychiatrists and other health professionals can do. Appropriate counseling may be very helpful here, for example. Body dissatisfaction can be tackled by helping to reshape the individual's distorted body image; if the individual can be encouraged to realize that media-presented images of the human body are not the norm and are indeed unattainable for the vast majority of people, this could be very helpful (Leone et al., 2005). Given that MD is associated with low self-esteem (Wolke and Sapouna, 2008), strategies to enhance self-esteem will likely also prove useful. It is important for such individuals to develop non-appearance based sources of self-esteem so they do not judge their worth as a human being solely through their muscularity. Developing other 
interests that can serve as sources of self-esteem may be crucial in weaning people off some of the unhealthy behaviors that occur with MD. Indeed, Vassallo and Olrich (2010) found that when AAS users developed other important life roles such as husband, father and businessman, they ceased AAS use as having a muscular physique was not seen as important to them any more. It should be recognized that individuals presenting with MD symptoms may not be at the point where they have other life roles that could easily replace that of 'bodybuilder', but certainly appropriate counseling may help individuals get to this point. Given that MD is strongly correlated with concurrent anxiety (Wolke and Sapouna, 2008), the psychologist should also teach coping strategies to ensure that MD-susceptible individuals are less likely to rely on maladaptive and unhealthy coping strategies such as AAS use.

It is important, however, that counseling is done in such a way that it is sympathetic to the individual's desire to achieve or maintain a high level of muscularity. Individuals with MD may worry that the healthcare professional may try to take away their ways of coping with their MD, such as extreme amounts of exercise, fad diets and drug use. Thus, simple suggestions made to them that they should stop such practices, with nothing to replace them that would help them maintain their quest for a muscular physique, are likely to fall on deaf ears. So, for example, such individuals could be advised to consult a qualified sports nutritionist to help them develop a healthy musclebuilding diet, and to possibly change their workout environment away from a 'hardcore' bodybuilding gym, which is an environment in which AAS use and obsessive and unhealthy training regimens often begin. As noted by Smith et al. (2009), the social environment in such gyms often encourages and reinforces the use of AAS, for 
example, and as such gyms typically contain AAS users, then this may also normalize the steroid-using physique to the other gym users. In addition, many AAS users purchase the drugs in these gyms (Smith et al., 2009). Therefore, other options should be examined such as facilities with a broader range of clientele, or home training.

Such strategies may help reduce the likelihood of AAS use, but care needs to be taken with those who are already using such drugs. Abrupt cessation of AAS use can lead to suicidal ideation (Thiblin, Runeson and Rajs, 1999), possibly due to testosterone levels becoming much lower than baseline, leading to depression. Therefore, when ceasing use AAS users should be referred to a physician with expertise in this area who can advise them on how best to cycle gradually off of AAS. Many bodybuilders use human chorionic gonadotrophin to maintain testosterone production when cycling off AAS use and thus avoid these problems; however, the effectiveness and safety of this still needs to be assessed in clinical research.

Interestingly, Pope, Philips and Olivardia (2000) report some individuals with MD being successfully treated with antidepressants such as fluoxitine. Unfortunately, the use of these drugs has been shown to lead to suicidal ideation in some patients (e.g. Mann and Kapur, 1991), and therefore given that the lower testosterone levels may already lead to depression when cycling off AAS, the use of such antidepressants may prove especially dangerous. Therefore, prescribing such drugs when individuals are coming off AAS is likely unwise. 


\section{References}

American Psychiatric Association, 2013. American Psychiatric Association Diagnostic and

statistical manual of mental disorders (5th ed.) Author, Washington, DC (2013).

Blouin, A. G., \& Goldfield, G. S. (1995). Body image and steroid use in male bodybuilders.

International Journal of Eating Disorders, 18(2), 159-165.

Kelly, M. M., Didie, E. R., \& Phillips, K. A. (2014). Personal and appearance-based rejection

sensitivity in body dysmorphic disorder. Body Image, 11(3), 260-265.

Maida, D. M., \& Lee Armstrong, S. (2005). The classification of muscle dysmorphia. International Journal of Men's Health, 4(1), 73-91.

Murray, S.B., Rieger, E., Touyz, S.W., et al. (2010) Muscle dysmorphia and the DSM-V conundrum: where does it belong? A review paper. International Journal of Eating Disorders 43: 483-491.

Murray, S. B., \& Touyz, S. W. (2013). Muscle dysmorphia: Towards a diagnostic consensus. Australian and New Zealand Journal of Psychiatry, 47(3), 206-207.

Olivardia, R., Pope, H. G., Jr., \& Hudson, J. I. (2000). Muscle dysmorphia in male weightlifters: 
A case-control study. The American Journal of Psychiatry, 157(8), 1291-1296. Phillips, K. A., Menard, W., Fay, C., \& Pagano, M. E. (2005). Psychosocial functioning and

quality of life in body dysmorphic disorder. Comprehensive Psychiatry, 46(4), 254-260.

Pope, H. G., Jr., Gruber, A. J., Choi, P., Olivardia, R., \& Phillips, K. A. (1997). Muscle dysmorphia: An underrecognized form of body dysmorphic disorder. Psychosomatics: Journal of Consultation and Liaison Psychiatry, 38(6), 548-557.

Pope, H. G., Katz, D. L., \& Hudson, J. I. (1993). Anorexia nervosa and "reverse anorexia"

among 108 male bodybuilders. Comprehensive Psychiatry, 34(6), 406-409.

Pope, H.G., Phillips K.A., \& Olivardia R. (2000). The Adonis Complex: The Secret Crisis of

Male Body Image Obsession. New York, NY: Free Press.

Pope, C. G., Pope, H. G., Menard, W., Fay, C., Olivardia, R., \& Phillips, K. A. (2005). Clinical

features of muscle dysmorphia among males with body dysmorphic disorder. Body Image, 2(4), 395-400.

Rohman, L. (2009). The relationship between anabolic androgenic steroids and muscle dysmorphia: A review. Eating Disorders: The Journal of Treatment \& Prevention, 17(3), 187-199.

Spence, J. C., McGannon, K. R., \& Poon, P. (2005). The effect of exercise on global self-esteem: 
A quantitative review. Journal of Sport \& Exercise Psychology, 27(3), 311-334.

Suffolk, M. T., Dovey, T. M., Goodwin, H., \& Meyer, C. (2013). Muscle dysmorphia: Methodological issues, implications for research. Eating Disorders: The Journal of Treatment \& Prevention, 21(5), 437-457.

Winett, R. A., \& Carpinelli, R. N. (2001). Potential health-related benefits of resistance training.

Preventive Medicine: An International Journal Devoted to Practice and Theory, 33(5), 503-513.

Lantz Rhea and Mayhew 